\title{
Choking with a snare to control immediate bleeding after cold snare polypectomy
}
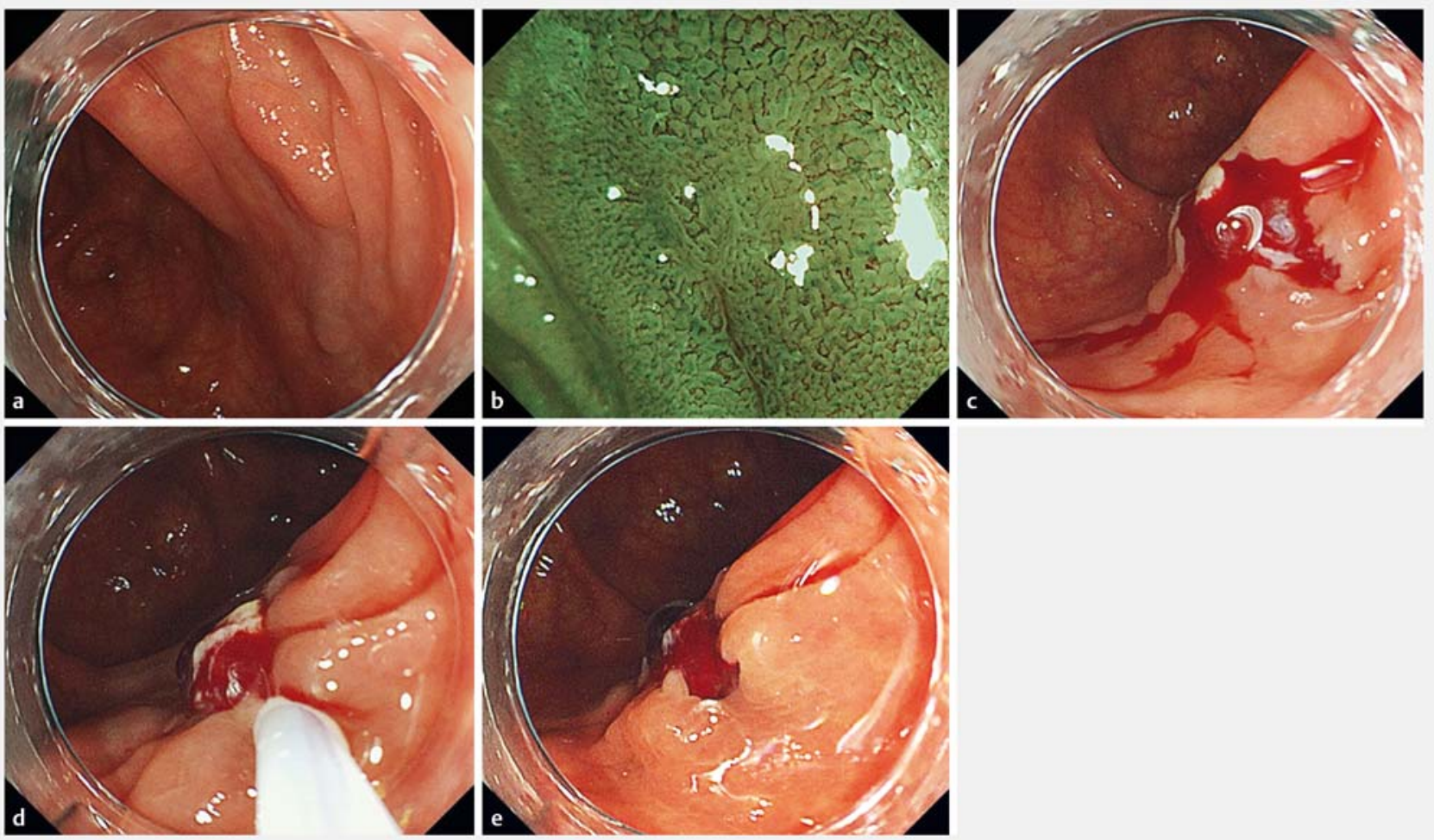

- Fig. 1 Colonoscopic views showing: a a 9-mm polyp (macroscopic type lla) in the transverse colon; b a JNET type 2A lesion on narrow-band imaging, indicating a low grade adenoma; c immediate bleeding from the mucosal defect after cold snare polypectomy, which continued for 60 seconds; $\mathbf{d}$ choking of the mucosal defect with the snare; e the appearance after hemostasis had been achieved by choking with the snare.

A 75-year-old man underwent surveillance colonoscopy after endoscopic submucosal dissection for an intramucosal adenocarcinoma in his transverse colon. Colonoscopy revealed a metachronous colonic polyp in the transverse colon (॰ Fig.1a). Macroscopically, this was a type 0 -Ila lesion and, according to the JNET classification [1], it was type 2A, indicating a low grade adenoma ( $\triangleright$ Fig. $1 \mathbf{b})$. Therefore, we performed cold snare polypectomy (CSP) using the Snare Master Plus (10 mm; SD-400U-10, Olympus, Tokyo, Japan). Bleeding continued for 60 seconds after CSP (immediate bleeding; - Fig. 1c), therefore we choked the mucosal defect, including the surrounding mucosa, with the same snare ( $\triangleright$ Fig. 1 d). We continued the choking for $30 \mathrm{sec}$ onds, which stopped the bleeding ( $\triangleright$ Fig.

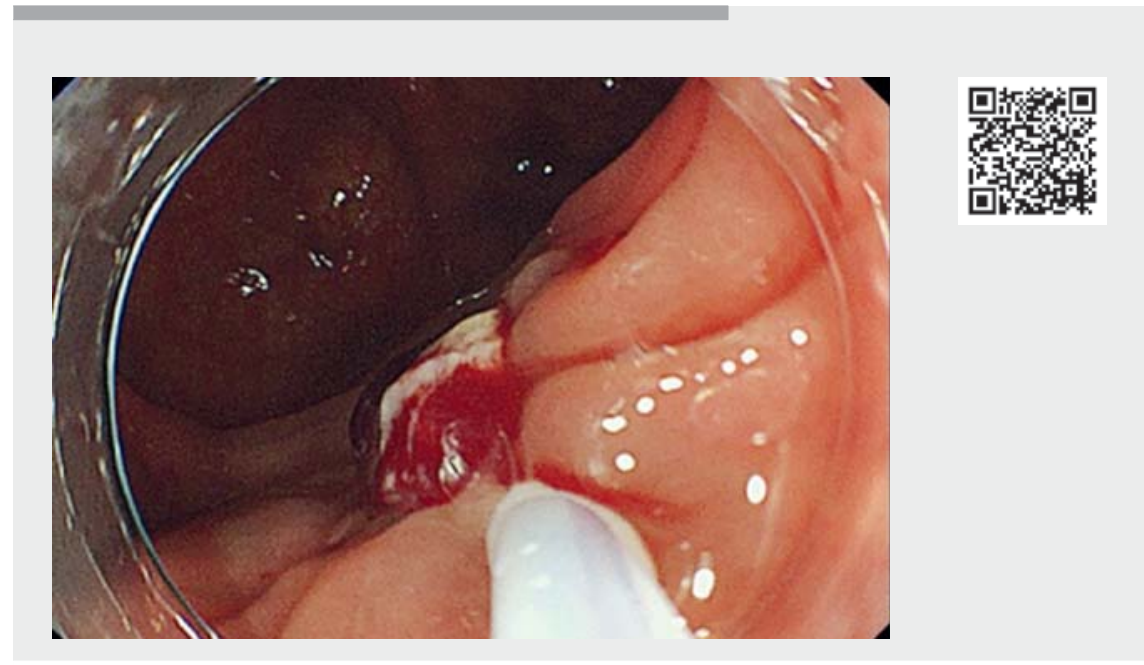

Video 1 Immediate bleeding after cold snare polypectomy is controlled by choking with the snare. 
1 e; V Video 1). There were no complaints of hematochezia thereafter. Pathologically, the polyp was a low grade tubular adenoma, with no involvement of the lesion at the cut margin.

CSP is widely performed for subcentimeter polyps, where less delayed bleeding, coagulation syndrome, and perforation are expected [2-5]. However, immediate bleeding sometimes occurs after CSP and hematochezia can cause anxiety [2, $3,5]$. In this case, choking with a snare enabled prompt and successful control of immediate bleeding, without the need to change to other devices, such as clips or hemostatic forceps.

Endoscopy_UCTN_Code_TTT_1AQ_2AD

\section{Competing interests}

Yoji Takeuchi received honoria from Olympus. The other authors declare that they have no conflict of interest.

The authors

Satoki Shichijo Koji Higashino, Noriya Uedo , Ryu Ishihara, Tomoki Michida, Yoji Takeuchi ${ }^{-}$

Department of Gastrointestinal Oncology, Osaka International Cancer Institute, Osaka, Japan
Corresponding author

\section{Satoki Shichijo, MD, PhD}

Department of Gastrointestinal Oncology, Osaka International Cancer Institute, 3-1-69, Otemae, Chuo-ku, Osaka, 541-8567, Japan 7satoki@oici.jp

\section{References}

[1] Sano Y, Tanaka S, Kudo SE et al. Narrowband imaging (NBI) magnifying endoscopic classification of colorectal tumors proposed by the Japan NBI Expert Team. Dig Endosc 2016; 28: 526-533

[2] Takeuchi Y, Mabe K, Shimodate Y et al. Continuous anticoagulation and cold snare polypectomy versus heparin bridging and hot snare polypectomy in patients on anticoagulants with subcentimeter polyps: a randomized controlled trial. Ann Intern Med 2019; 171: 229-237

[3] Shichijo S, Takeuchi Y, Kitamura M et al. Does cold snare polypectomy completely resect the mucosal layer? A prospective single-center observational trial. J Gastroenterol Hepatol 2020; 35: 241-248

[4] Takeuchi Y, Yamashina T, Matsuura N et al. Feasibility of cold snare polypectomy in Japan: A pilot study. World J Gastrointest Endosc 2015; 7: 1250-1256

[5] Kawamura T, Takeuchi Y, Asai S et al. A comparison of the resection rate for cold and hot snare polypectomy for $4-9 \mathrm{~mm}$ colorectal polyps: a multicentre randomised controlled trial (CRESCENT study). Gut 2018; 67: 1950-1957
Bibliography

Endoscopy 2022; 54: E123-E124

DOI 10.1055/a-1418-8046

ISSN 0013-726X

published online 16.4.2021

(c) 2021. Thieme. All rights reserved.

Georg Thieme Verlag KG, Rüdigerstraße 14,

70469 Stuttgart, Germany

\section{ENDOSCOPY E-VIDEOS \\ https://eref.thieme.de/e-videos}

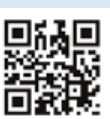

Endoscopy E-Videos is an open access online section, reporting on interesting cases and new techniques in gastroenterological endoscopy. All papers include a high quality video and all contributions are freely accessible online. Processing charges apply (currently EUR 375), discounts and wavers acc. to HINARI are available.

This section has its own submission website at https://mc.manuscriptcentral.com/e-videos 